Jurnal Keperawatan Padjadjaran)

ISSN 2338-5324 (print)

ISSN 2442-7276 (online)

Online di http://jkp.fkep.unpad.ac.id

DOI : $10.24198 / \mathrm{jkp}$

\title{
Nursing Students' Roles and Experiences of Disasters in A Nursing School
}

\author{
Sri Hindriyastuti ${ }^{1}$, Mayumi Kako ${ }^{2}$, Jamie Ranse ${ }^{3}$, Alison Hutton ${ }^{4}$ \\ ${ }^{1}$ Cendekia Utama Kudus Health Collage, Kudus, Indonesia \\ ${ }^{2}$ School of Nursing and Midwifery, Flinders University, Adelaide, Australia \\ ${ }^{3}$ School of Nursing and Midwifery, Griffiths University, Australia \\ ${ }^{4}$ School of Nursing and Midwifery, Newcastle University, New South Wales, Australia \\ Corresponding Email: Alison.hutton@newcastle.edu.au
}

Submitted: 04-09-2018 Accepted: 29-03-2019 Published: 12-04-2019

\begin{abstract}
Due to its location on the 'Pacific Ring of Fire', Indonesia is often prone to natural disasters. Therefore, Indonesian nurses need to have the ability to assist in disaster situations because they are considered one of the important elements of the workforce in disaster preparedness and response. However, the current nursing curriculum in Indonesia does not adequately prepare nurses to respond to this situation. The main objective of this study is to understand the role experiences of Masters of Nursing students and experiences in disaster settings in a nursing school in East Java, Indonesia. A single case study design has been used. Data collection was carried out through semi-structured interviews. The participants are registered in the Master of Nursing program in the School of Nursing at a University in East Java. The data for research were analysed thematically. Four main themes were identified: 'personal feelings', 'working outside their scope of practice', 'lack of disaster preparedness', and 'lack of mental health care and knowledge'. This study found that students of a Masters in Nursing at a nursing school in East Java, Indonesia were not adequately prepared to face disaster situations. This study found that working outside the scope of practice and lack of mental health knowledge were the main problems for these Master of Nursing students. Apart from starting disaster training early in their education, it is recommended to provide training in the psychological context of disaster preparedness.
\end{abstract}

Keywords: Disaster, Indonesia, nursing, nursing students, nursing roles. 
Sri Hindriyastuti: Nursing Students Roles and Experiences of Disasters in A Nursing School

\section{Introduction}

The United Nations International Strategy for Disaster Reduction (UNISDR) defined a disaster as:

"A serious disruption of the functioning of a community or a society at any scale due to hazardous events interacting with conditions of exposure, vulnerability and capacity, leading to one or more of the following: human, material, economic and environmental losses and impacts. (UNISDR, 2017, terminology on disaster risk reduction section)."

In 2015, 998 million people were affected by disasters, with 22,773 losing their lives. In total, 345 disasters were recorded with the majority of these happening in the AsiaPacific region, and a total of 11 occurring in Indonesia (UNISDR, 2014). Disasters in Indonesia are predominantly geophysical or hydrological in nature. The Indonesian National Disaster Management Authority (2015) reported that, in 2014, 425 disasters struck Indonesia causing 206 deaths and 1,505 injuries, with 41 people missing. In 2015 , there were 1,116 disasters with 186 deaths, and affecting a further 636,205 people, with 9,557 survivors being evacuated (The Indonesian National Disaster Management Authority, 2015).

These ongoing situations have heightened recognition of the role of nurses in disaster management and response (Veenema, 2018). As an important part of the health disciplines, nurses are on the frontline of responding to disasters (Cusack, Arbon \& Ranse, 2010). However, Chapman and Arbon (2008) have asserted that it is not only nurses who need to respond to disasters, but also nursing students. In western countries, nursing students have been involved in responding to emergency situations, including disasters such as that which occurred in Haiti, and the cases of Tropical Cyclones Debbie and Irene (American Red Cross, 2012). Therefore, providing nursing students with disaster preparedness training is crucial to ensuring that they are well-prepared for disaster situations (Chapman \& Arbon, 2008).

Disaster preparation education has been established in several schools of nursing in the United States of America (USA) by developing a variety of programs ranging from certificates to master's degrees (Veenema, 2018) (see Table 1). These schools include, but are not limited to, Adelphi University (a Graduate Certificate in Emergency Management), Johns Hopkins University (Master of Science in Nursing Health Systems Management: Emergency Preparedness/Disaster Response), St. Louis University (online certificate program of Disaster Preparedness for Nurses), Grand Valley State University (a series of lectures for senior nursing students on the threats of bioterrorism agents and re-emerging infections), and University of Texas at Austin (Initiatives for Mass Casualty Education course) (Veenema, 2018).

These programs provide opportunities for practicing nurses to prepare appropriate responses to catastrophic, mass casualty events and public health emergencies (Veenema, 2018). Moreover, these educational programs support a wider strategy of preparing nursing students for disaster events (Hutchinson, et al., 2011). Moreover,

Table 1 Universities Providing Disaster Nursing Courses in United States (Veenema 2018)

\begin{tabular}{ll}
\hline \multicolumn{1}{c}{ Universities } & \multicolumn{1}{c}{ Course } \\
\hline Adelphi University & Graduate certificate of Emergency Management), \\
Hopkins University & Master of Science in Nursing Health Systems \\
& Management: Emergency Preparedness/ Disaster \\
& Response \\
Online certificate program of Disaster Preparedness & for Nurses), \\
St. Louis University & $\begin{array}{l}\text { A series of lectures for senior nursing students on } \\
\text { the threats of bio-terroristic agents and remerging } \\
\text { infections), }\end{array}$ \\
Grand Valley State University & Initiatives for Mass Casualty Education course) \\
\hline
\end{tabular}


Sri Hindriyastuti: Nursing Students Roles and Experiences of Disasters in A Nursing School

Olivia, Claudia and Yuen (2009) argued that disaster preparedness content delivered within a school of nursing will develop and enhance nurses' preparedness for emergency cases in the future.

International Council of Nurses (ICN) has established the minimum standard of nursing disaster curricula to be applied in nursing schools. This curricula covers the basic standard of nursing competencies in order to be ready to participate in disaster situations, including mitigation, preparedness, response, and recovery programs (World Health Organisation 2009).

In 2015 the The Association of Indonesian Nurse Education Center (AINEC) established a curriculum for Bachelor of nursing program. This curriculum contained a disaster nursing subject (AINEC 2015; Hermawati, Hatthakit, \& Chaowalit 2010). Indonesian nursing students in East Java receive two units of disaster nursing content in their seventh semester of undergraduate nursing program. This module covers the International Council of Nursing (ICN) disaster nursing competencies (AINEC 2015). This unit, however, is not enough to adequately prepare nursing students to be fully ready to assist in a disaster area (Hermawati, Hatthakit, \& Chaowalit 2010). Generally, disaster nursing content is not available in Master's curriculum in Indonesia. However, Master's of Nursing in limited universities provide elective program such as seminars, training and disaster drills. One of these universties is a university in East Java. Therefore, the Kelud Eruption occurred in East Java in 2014, many Master students from the school were involved in assisting during this situation. However, even with the current training, the experience of these students providing care in disasters is unknown. In addition, the experience of nursing students in lower middle income countries, such as Indonesia are under represented in the disaster literature Therefore, this study will focus on exploring the experience of Master's of nursing students in responding to a disaster in East Java, Indonesia.

\section{Method}

While the focus of this study lends itself to the potential use of one of several qualitative traditions or methodologies, the case study method was chosen. Case study is an approach summarised in-depth investigation of experience in the diversity of the social environment under study (Hentz, 2007). It was envisaged that the complexity of the student experience of working in a disaster would be described holistically through the case study method. Purposive sampling was employed in this study. It was possible that some of the participants might experience anxiety or have an emotional reaction when discussing their experiences in disaster setting. Therefore, enabling participants to come forward and identify themselves voluntarily was important.

Data collection was conducted through semi-structured interviews. The researcher interviewed seven participants until data saturation had been reached. Data saturation is the point in the research process when no new information is discovered in data analysis, this point was reached after seven interviews (Fusch and Lawrence, 2015).

All participants provided care after the Kelud volcanic eruption, while one participant also experienced providing care during a flood. Of the seven participants, five had responded to a disaster once, one had responded twice, and another four times. These students were enrolled in a general Master of Nursing course concerned with specialty areas of practice, including critical care nursing, and mental and community health.

The setting for the study is a university in East Java, Indonesia. The location was chosen specifically because there was a disaster (Kelud Eruption) in February 2014. This research was conducted a year after the catastrophic event. Moreover, this nursing school provides disaster seminar and drills in the second semester of its Master's program. Further recruitment criteria included being over 18 years of age, and participating in disaster settings from 2012 to 2014.The data collection was conducted in 2015 
Sri Hindriyastuti: Nursing Students Roles and Experiences of Disasters in A Nursing School

through semi-structured interviews as the data collection method. As part of this, the researcher provided a set of questions as a guide for the interviews. All interviews were conducted in a private secure room at the university. Each interview took between 60 to 90 minutes for each participant, and all participants gave informed consent. The interviews were audio recorded. Ethics approval was sought and gained for this study at Flinders University (SBREC6336) as well as the Ethics Committee of the Cendekia Utama Kudus Health Collage in Indonesia (380/EC/KEPK-S2/06/2014).

A thematic analysis was used to generate the initial findings from the data resulting in four main themes being used to present the overall findings of the study. Thematic analysis was used to analyse the data. An inductive, semantic approach to thematic analysis was selected, as this method supported the exploratory nature of the study and ensured that the themes identified were strongly linked to the collected data (Braun \& Clarke, 2013).

Following Braun and Clarke's (2013) process, the data was analysed using six steps. Firstly, the researcher familiarised herself with the data through the transcription process. In this step, the researcher transcribed the interview data into written form. Transcribing the data into text enables the researchers to deeply understand the data and check its rigour and accuracy. The second step is to generate initial codes, and then to collate data. This is followed by the third step, which involves the researcher looking for the broader meaning of the data through generating codes to develop main themes and sub-themes. Step four involves two phases consisting of reviewing the themes that have emerged during step three (reviewing the level of the coded data and refining the entire data set). Step five consists of defining and naming the themes, and identifying the essence of each theme. The final step consists of the researchers writing up a final report of the themes (Braun \& Clarke, 2013).

To gain trustworthiness within a qualitative study the data must ensure faithful descriptions of the subjective interpretations of participants (Munhall, 2012). In this study each transcript was taken back to each participant for verification. In addition, through using the six steps of data analysis by Braun and Clarke (2013) a decision trail was created that can then be replicated by other researchers, thus enhancing trustworthiness of the data (Munhall, 2012).

How the researcher(s) maintain the Trustworthiness? Otherwise we cannot believe the results.

\section{Result}

This study found that the majority of Master of Nursing students believed that participating in disaster settings created a challenging work environment for them, due to their limited ability to cope with personal feelings, working outside their scope of practice, lack of disaster preparedness, and a lack of mental health knowledge and care.

\section{Personal feelings}

In this study, common feelings experienced by the participants were identified as worry, anxiety, and confusion in the pre-disaster response.

I felt anxious, yes ... I was also anxious when I was going to the disaster area ... Was it going to be okay or worse? You know, it (the volcano) was erupting. Eruption of Kelud was not only once. There were sudden tremors and smoke (Participant 1).

Anxiety was experienced when the participants thought about the potential chaotic situation of the disaster setting. Additionally, six of the seven participants felt worried and anxious about whether or not they could be of any help during the disaster. I was afraid, worried, and confused before going there [to the disaster setting]. "Can I help them? [the disaster survivors]" (Participant 2).

... before knowing the situation in the disaster setting ... there were two possibilities ... "Is it okay to be there? ... am I safe there? Or maybe will be like a victim as well?" ... I felt anxious (Participant 4).

Before going there ... I was so worried ... 


\section{Sri Hindriyastuti: Nursing Students Roles and Experiences of Disasters in A Nursing School}

I was worried if I could not do anything there (Participant 5).

However, once they were in the disaster area, they felt relieved and eager to be participating. Yes... and after I arrived there [in the disaster area], I enjoyed it... not worried anymore... we worked in a team.. so ..it was memorable time, we can help others (the victims) (Participant 1).

I was worried at first .. again. However, when we arrived there.. I was so relieved... it was different from what I thought beforehand. (Participant 5).

All the participants stated that they were able to manage their personal feelings during disaster response. In the post-disaster phase, most participants also experienced positive personal feelings. Participants felt relieved and happy as they had gained more experience compare to their friends who had not volunteered. They thought that they not only attained disaster concept through their education, but were also able to practice it in a real situation. This was a positive overall aspect for them.

...yes... hmmm... ah, after volunteering and we were home, for sure we felt so relieved ... we had finished ..//.. finally, finished. By the way, I have an additional positive aspect. For most of my clasmates, participation in a disaster setting was only as concept in a class, but for us... for those who participated in the Kelud eruption, they experienced the real situation. Lucky me! I had been involved directly. It was a positive point for me. Well, it was my feeling when arrived home. (Participant 1)

...yes. In post-disaster ... I think ... there is such a personal satisfaction ... so proud of myself ... first, because we have the real experience, second because we helped to save the patients and their families. I think I did not have any traumatic feelings although it was my first time there ... but, I was motivated enough ... full of spirit. If there is another disaster, I will participate ... if possible. We can save other people, can't we? (Participant 4).

Students were worried, anxious and confused before taking part in the disaster event. However, once they were at the affected area, they were able to participate and could manage their own feelings. During the postdisaster phase, all participants experienced positive feelings such as happiness, interest, and motivation. Consequently, with the positive outcomes of their experiences, they wanted to participate in disaster responses in the future.

Working outside the normal scope of practice

A major concern for the nursing students interviewed was the expectation that in disaster work, they were expected to work outside their scope of practice. Students mentioned that in the disaster situation, they needed to help other volunteer health professionals. For example, they were asked to stitch wounds and give prescriptions to patients, duties that are normally a medical officer's responsibility. This concern is illustrated by Participant 6 ,

The number of doctors was very limited ... nurses were also taking part in some medical activities ... although maybe it was not our responsibility. The situation required us to ... when there were some patients with wounds ... we did wound care ... stitched the wound ... and also giving prescriptions to the patients ... So [whether] we wanted it or not, we had to do it. It was an unpredictable situation ... an emergency situation (Participant 6).

As the disaster setting was an emergency situation, the participants felt that they should take action as soon as possible and fill in any gaps as needed. Five participants mentioned that in order to support each other in the disaster setting, doing the jobs of other professionals was a must. We helped doctors in giving medications and we infused patients as well ... (Participant 5).

We collaborated with doctors in handling the patients and treating the wounds (Participant 2).

Due to the limited number of people volunteering, most of the participants mentioned that their jobs needed to be flexible while in the disaster area. Furthermore, unclear job descriptions and expectations within the disaster setting challenged them. Yes, it was not clear ... our job description was not clear. For example, there was a case, when there was an emergency call, and we had no job description beforehand, we were 
Sri Hindriyastuti: Nursing Students Roles and Experiences of Disasters in A Nursing School

confused about it, who should be in triage, who should be here ... who should be there. So, everyone was asked to be there randomly to an emergency call. There was no clear job description (Participant 3).

Due to the limited numbers of people volunteering, most of the participants mentioned that their jobs needed to be flexible while in the disaster area. On occasions, other volunteers would ask them to take over their jobs; for example, nursing students were asked to handle and distribute the logistics of food delivery and distribution to the evacuation area. I was also asked to assist in handling many jobs..such as... helping army in providing food to the victims of disaster... (Participant 1)

At that time, food was abundant, but it was not distributed well ... only in one area.. So, we helped to bring the food to other evacuation area. (Participant 3 )

In relation to providing appropriate services to the community during the disaster response, there were unclear job descriptions for the participants in this study. This was further exacerbated by a shortage of health professionals working in the affected area, meaning that nursing students were often left to do the tasks of other professions. To summarise this theme, nursing students experienced a challenging work situation due to often undertaking work which was outside of their normal scope of practice.

\section{Lack of disaster preparedness.}

The participants in this study talked about the lack of disaster preparedness. Due to the large number of disasters in Indonesia, all the participants thought that becoming competent in disaster nursing was crucial in order to support their disaster preparedness. The participants claimed that their knowledge of disasters was deficient in terms of disaster concepts, including simulations, and research about disasters.

In my undergraduate program, it [the curriculum] was so general... (Participant 4).

Five participants agreed that it would be beneficial if disaster content was taught earlier in their overall education.

Honestly, we needed to learn disaster theory in our bachelor's degree or the diploma. So far, in the master's program, the theory was very general. Not enough [about disasters] ... it was limited ... yes (Participant 7).

We did not need only theory, but also simulations and trainings as well ..., more practical skills are needed. Not only the theory ... in both of them [undergraduate and postgraduate programs] (Participant 2).

The participants were interested in learning about disaster preparedness in the Master of Nursing program and how to respond to chaotic situations. Three of the participants stated that receiving disaster education from an early age was very important. Participants believed that children, for example, should receive a basic disaster education when they are in elementary school. Learning about disaster theory in their Master of Nursing program was beneficial, but the participants stated that they would have preferred to have learned this earlier in their academic career.

We have learned more in the master's program ... I have learned more ... the theory of the pre-and in-hospital program, how to evacuate patients as well. Therefore, when we were in the disaster program, we could help more. Maybe because we learn new competencies based on the American Nurses Association (Participant 6).

Overarching concepts of what happens in a disaster was described as being ineffective and needing improvement. Moreover, they also believed that both undergraduate and postgraduate nursing students needed more disaster training. The participants recommended that the availability of a disaster research laboratory on the university campus would enable students to conduct research on disasters. Furthermore, the participants mentioned that such research could provide recommendations in relation to what volunteers should do when taking part in a disaster situation.

Research can give a recommendation in specific disaster situations. I think there is still no research in disaster settings in Indonesia, especially in our campus (Participant 6).

Overall, the participants stated that disaster concepts, training, and research taught by Indonesian schools of nursing, as well as that learned outside of these schools, was insufficient. The participants identified this as the major factor that had an impact on their ability to participate successfully in 
Sri Hindriyastuti: Nursing Students Roles and Experiences of Disasters in A Nursing School

disaster responses.

Lack of mental health knowledge and care During the disaster response, students encountered patients with mental healthrelated issues. The participants stated that they tried to provide holistic care to the patients through therapeutic communication. However, they believed that they had little knowledge of how to care for these patients' mental healthcare needs. An example given by Participant 4 stated that, as part of their duties, they needed to persuade people to evacuate from their homes and leave their properties unoccupied. This process was not easy because most of the victims did not want to leave, as they wanted to keep their belongings safe. For some people, this was all they owned. Therefore, the participants believed that they needed to be taught how to care for distressed people during their nursing studies.

A sensitive approach was needed to persuade people to evacuate ... because they thought that their property like house, land ... or their pets were more important, so they tended to stay there than evacuate to the evacuation area. In this case, we had to persuade them to follow our instructions in the evacuation process (Participant 4).

... when we evacuated them ... some of them did not want to be evacuated ... so ... yes, so we forced them, but not arrogantly, softly, this is what we call ... caring ... yes ... caring ... they did not want to leave their belongings ... and we had to understand that (Participant 7).

Additionally, the participants stated that they needed to be silent and listen to the concerns of the people affected by the disaster. They also stated that it was primarily the female students who communicated with the affected people, as they were considered to be calmer, and could control their emotions. Thus, the participants in this study proposed that learning about theory and taking part in simulations focusing on the mental health aspects of patient care were needed. Participant 6 stated that there was a patient with a mental health problem and his team was not able to provide effective therapy or holistic care. As a result, his senior colleague, a nurse who worked in a psychiatric hospital, handled the case.
We could not do anything to the patient, it was done by Mr. A. He just finished his master's study in our nursing school. He did the therapy of the patient until her condition was getting better. So calm ... not hysterical ... no panic anymore. Yes, lucky us, there was Mr. A at that time. Finally, she was able to walk back home ... we should not let patients like her feel so sad with her own feelings for such a long time. I highlighted that it was important to focus on mental problems as well. We have to learn holistic care ... psychological, physical, social aspects as well. If we do not know all these aspects, we will have difficulties in the real situation, especially in disaster settings (Participant 6).

The importance of studying mental health was also mentioned by Participant 2 who stated that in the recovery phase, nurses should be able to assess patients' mental health.

It [the mental health program] was outside the subject, outside the curriculum. As we did not learn it at our campus, we did not practice it in the disaster situation. We did not explore the condition of those patients with non-physical trauma. Honestly, it was very much needed in the disaster ... it was very important (Participant 2).

The small cohort in this study felt that specific education in mental health and mental illness would be beneficial for them when responding to disaster situations.

\section{Discussion}

The Master of Nursing students involved in this study were worried and anxious before taking part in the disaster event. However, once they were in the disaster area, they were able to participate and could manage their own feelings well and focus on the job at hand. Fothergill, Palumbo, Rambur, Reinier and McIntosh (2005) stated that personal feelings, worry, and anxiety prior to participation in a disaster setting is experienced by nurses before taking part in any disaster response. Hammad, Arbon, Gebbie and Hutton (2012) added that personal emotions such as fear and anxiety affected nurses prior to their participation in disaster response. Several authors have found that these feelings can 
Sri Hindriyastuti: Nursing Students Roles and Experiences of Disasters in A Nursing School

decrease the willingness to respond to disasters (Considine et al., 2011).

However, in the study reported here, these thoughts and emotions were managed by all the participants due to the willingness to help others. Once the Master of Nursing students were in the disaster location, their negative feelings turned to constructive thoughts and they became excited and interested in the job at hand. Fothergill et al. (2005) supported this finding and argued that a commitment to helping other people supports nurses' willingness to volunteer in disaster settings. In addition, responding to a disaster allows nurses to have positive personal feelings about being part of the disaster response which then supports their willingness to participate in future disaster responses (Fitzgerald et al., 2010; Hammad et al., 2012).

As part of their role in the disaster area, the students were asked to perform unfamiliar procedures that they did not do in their usual practice. They performed these tasks because of the emergency situation and the limited number of health workers in the field. Working outside the normal scope of practice is not new and is part of the work required in most disaster settings (Baack \& Alfred 2013). Arbon et al. (2006) and Chapman and Arbon (2008) found that in these situations, nurses are frequently asked to do jobs outside their scope of practice, regardless of whether they are qualified or not. Gallardo et al. (2015) found that nursing students with more experience in disaster settings performed medical treatments outside of their scope of practice. It is not clear if the Master of Nursing students in this study were legally covered to work outside their scope of practice, or whether or not Indonesia has a modified practice authority for student nurses in disaster settings (Association of State and Territorial Health Officials 2012).

The students in this study not only worked outside of their scope of practice, they also performed other tasks unrelated to nursing such as handling the logistics of food. Gebbie and Qureshi (2002) found that this is another common occurrence with nurses often assisting operations officers in logistics, planning, finance, and administration. The participants believed that disaster content should be learned by nursing students as early as possible in undergraduate studies. They suggested that the undergraduate program of nursing would be the best educational level to introduce them to disaster content. This is not a new finding and many studies have argued for undergraduate programs to include disaster nursing (Usher \& Mayner, 2011; Oztekin, Larson, Ugras \& Yuksel, 2013; Peoples, Gebbie \& Hutton, 2015). The participants in this study stated that they had received specific disaster content in their master's programs. However, they felt that this education did not meet all their needs in the disaster setting. They wanted to understand the role of government, undertake disaster training drills, and learn about disaster preparedness. Ireland, Emerson, Kontzamanis and Michel (2006) found that incorporating disaster training in the undergraduate program of nursing is helpful for enhancing nursing students' knowledge of disaster environments.

Disaster education and training are considered as effective ways to improve nursing students' knowledge of disasters (Kaplan, Connor, Ferranti, Holmes \& Spencer, 2012). Disasters are chaotic situations which can contribute to the mental illness of survivors (Ranse, Hutton, Wilson \& Usher, 2015), which is not uncommon in these circumstances. Warsini, West, Mills and Usher (2014) found that patients not only suffered from mental illness, but also identified as being anxious, depressed, having post-traumatic stress disorder, and having a heightened suicide risk (Warsini et al., 2014). Consequently, affected people need comprehensive psychiatric nursing care (Montazeri \& Baradaran, 2005). However, all the participants lacked mental health knowledge and felt that they were unable to cope with this situation. Ranse, Hutton, Jeeawody and Wilson (2014) found that nurses identified the psychosocial aspects of disaster nursing as an important area for further research, as was improvement to clinical practice including training and curriculum development.

In order to be able to take care of patients with mental illness in the post-disaster phase, Nasrabadi, Naji, Mirzabeigi and Dadbakhs (2007) recommended that nurses be trained in mental health care prior to disaster response. 
Sri Hindriyastuti: Nursing Students Roles and Experiences of Disasters in A Nursing School

Although undergraduate and postgraduate nursing schools have established disaster curricula, mental health disaster content is still lacking (Ranse et al., 2015). Therefore, providing training in the psychological context of disaster preparedness in schools of nursing is a recommendation of the participants in this study in order to prepare them for dealing with the mental health problems that arise during disasters. Ranse et al. (2015) recommended that the availability of psychological disaster programs in nursing education is necessary to enhance nurses' and nursing students' preparedness to assist during disaster response.

Nursing students believed that disaster nursing preparedness would impact positively on their knowledge and roles in disaster responses. However, this is an area of research yet to be explored in this setting. In addition, exploring nurses' perspectives in providing mental health support to the patients in the disaster setting may uncover the need of specific psychological contents suitable to be established in nursing curricula of nursing schools in Indonesia. Further research is needed to understand more of these issues.

Qualitative studies elicit data from a small sample size; thus, the findings of this research may not be representative of the greater population of nursing students. Another limitation is that all the participants were Master of Nursing students. Despite these identified limitations, this research contributes to knowledge of nursing students' experiences in the disaster setting. As such, it provides an initial starting point for further research.

\section{Conclusion}

This research provides an insight into nursing students' experience of Master's of Nursing students in responding to a disaster settings in Indonesia. To capture the entire picture of Indonesian Master of Nursing students' participation in the disaster setting, and understand the perspective of nurses in lower middle income countries, further investigation should be undertaken. This study has found that student concerns, a challenging work environment, different roles, and the lack of disaster preparedness all contribute to the nursing students' experience of disaster response in Indonesia. This study has found that these factors need to be improved and has made recommendations to commence training earlier in nursing education and to include training in mental health nursing in Indonesia's nursing schools.

\section{References}

American Red Cross. (2012). Disaster services connection \#182. Retrieved from http://www/redcross.org/about-us/history/ red-cross-american-history/nursing.

Arbon, P., Bobrowski, C., Zeits, K., Hooper, C., Williams, J., \& Thitchener, J. (2006). Australian nurses volunteering for the Sumatra-Andaman earthquake and tsunami of 2004: A review of experience and analysis of data collected by the Tsunami Volunteer Hotline. Australasian Emergency Nursing Journal, 9(4), 171-178.

Association of State and Territorial Health Officials (ASTHO). (2012). Scope of Practice Toolkit. Retrieved from http://www.astho. org/uploadedFiles/Programs/Preparedness/ Public_Health_Emergency_Law/Scope_of Practice Toolkit/04-SOP\% $20 \mathrm{~S} \% 20$ of $\% 2 \overline{0}$ Pract $\% 20$ FS\%203-12\%20Final.pdf.

Baack, S., \& Alfred, D. (2013). Nurses' preparedness and perceived competence in managing disasters. Journal of Nursing Scholarship, 45(3), 281-287.

Chapman, K., \& Arbon, P. (2008). Are nurses ready? Disaster preparedness in the acute setting. Australasian Emergency Nursing Journal, 11, 135-144.

Considine, J., Shaban, R., Patrick, J., Holzhauser, K., Aitken, P., Clark, M., \& Fitzgerald, G. (2011). Pandemic (H1N1) 2009 influenza in Australia: absenteeism and redeployment of emergency medicine and nursing staff. Emergency Medicine Australia, 23, 615-623. 
Sri Hindriyastuti: Nursing Students Roles and Experiences of Disasters in A Nursing School

Cusack, L., Arbon, P., \& Ranse, J. (2010). What is the role of nursing students and schools of nursing during disaster? A discussion paper. Collegian, 17(4), 193-197.

Fusch, P., \& Lawrence, R. (2015) Are we there yet? Data saturation in Qualitative Research, The Qualitative Report, 20(9), 1408-1416.

Fitzgerald, G., Shaban, R., Arbon, P., Aitken, P., Considine, J., Clark, M., \& Hurst, C. (2010). Pandemic (H1N1) 2009 Influenza Outbreak in Australia: impact on emergency departments. Queensland University of Technology.

Gallardo, A. R., Djalali, A., Foletti, M., Ragazzoni, L., Della Corte, F., Lupescu, O., ... \& Fisher, P. (2015). Core competencies in disaster management and humanitarian assistance: a systematic review. Disaster medicine and public health preparedness, 9(4), 430-439.

Gebbie, K., \& Qureshi, C. A. (2002). Emergency and disaster preparedness. The American Journal of Nursing, 102(1), 46-52.

Hammad, K. S., Arbon, P., Gebbie, K., \& Hutton, A. (2012). Nursing in the emergency department (ED) during a disaster: a review of the current literature. Australasian Emergency Nursing Journal, 15(4), 235-244.

Hentz, P. B. (2007). Case study: The method. In P.L Munhall (Ed.), Nursing research: $A$ qualitative perspective (4th ed). Sudbury, MA: Jones \& Bartlett.

Hermawati, D., Hatthakit, U., \& Chaowalit, A. (2014). Nurses 'preparedness of knowledge and skills in caring for patients attacked by tsunami in indonesia and its relating factors.

Hutchinson, S. W., Haynes, S., Parker, P., Dennis, B., McLin., C., \& Welldaregay, W. (2011). Implementing a Multidisciplinary Disaster Simulation for Undergraduate Nursing Students. Nursing Education Perspectives, 32(4), 240-243.

Ireland, M., Emerson, E., Kontzamanis., E., \& Michel, C. (2006). Integrating Disaster
Preparedness into a Community Health Nursing Course: One School's Experience. Disaster Management \& Response, 4(3), 72-76.

Kaplan, B. G., Connor, A., Ferranti, E. P., Holmes, L., \& Spencer, L. (2012). Use of an emergency preparedness disaster simulation with undergraduate nursing students. Public Health Nursing, 29(1), 44-51.

Montazeri, A., \& Baradaran, H. (2005). Psychological distress among Bam earthquake survisors in Iran: a population based study. BMC Public Health, 5(1), 4.

Munhall, P. L. (2012). Nursing research: a qualitative perspective (5th ed.). United States of America: Jones and Barlett Publishers, Inc.

Nasrabadi, A. N., Naji, H., Mirzabeigi, G., \& Dadbakhs, M. (2007). Earthquake relief: Iranian nurses' responses in Bam, 2003, and lessons learned. International Nursing Review, 54(1), 13-18.

National Standards for Higher Education. (2015). Standar Nasional Pendidikan Tinggi (SN DIKTI).

Olivia, F. W., Claudia, L. K., \& Yuen, L.A. (2009). Nurses' perception of disaster: implications for disaster nursing curriculum. Journal of Clinical Nursing, 18(22), 31653171.

Oztekin, S. D., Larson, E. E., Altun Ugras, G., \& Yuksel, S. (2013). Educational needs concerning disaster preparedness and response: A comparison of undergraduate nursing students from Istanbul, Turkey, and Miyazaki, Japan. Japan Journal of Nursing Science.

Peoples, K., Gebbie, K., \& Hutton, A. (2016). An exploration of perceptions of disaster nursing and disaster preparedness amongst Australian nursing undergraduates. Health and Emergency Disaster Nursing, 2(4).

Ranse, J., Hutton, A., Jeeawody, B., \& Wilson, R. (2014). What are the research needs for the field of disaster nursing? An 
Sri Hindriyastuti: Nursing Students Roles and Experiences of Disasters in A Nursing School

international Delphi study. Prehospital and Disaster Medicine, 29(5), 1-7.

Ranse, J., Hutton, A., Wilson, R., \& Usher, K. (2015). Leadership opportunities for mental health nurses in the field of disaster preparation, response, and recovery. Issues in mental health nursing, 36(5), 391-394.

Suserud, B. O. (1993). Acting at a disaster site: views expressed by Swedish nursing students. Journal of Advanced Nursing, 18, 613-620.

The Assosciation of Indonesian Nurse Education Center. (2015). Kurikulum inti pendidikan ners Indonesia.

United Nations International Strategy for Disaster Reduction [UNISDR]. (2017). Terminology on Disaster Risk Reduction. Retrieved from https://www.unisdr.org/we/ inform/terminology.

United Nations International Strategy for Disaster Reduction [UNISDR]. (2014). Disasters in numbers. Retrieved from https:// www.unisdr.org/files/47804_2015disastertre ndsinfographic.pdf.
Usher, K., \& Mayner, L. (2011). Disaster nursing: A descriptive survey of Australian undergraduate nursing curricula. Australasian Emergency Nursing Journal, 14(2), 75-80.

Veenema, T. G. (Ed.). (2018). Disaster nursing and emergency preparedness. Springer Publishing Company.

Warsini, S., West, C., Mills, J., \& Usher, K. (2014). The psychosocial impact of natural disasters among adult survivors: an integrative review. Issues in Mental Health Nursing, 35, 420-436.

Wilson, R., \& Usher, K. (2015). Leadership opportunities for mental health nurses in the field of disaster preparation, response, and recovery. Issues in Mental Health Nursing, 36, 391-394.

World Health Organization. (2009). International Council of Nursing. ICN Framework of Disaster Nursing Competencies; World Health organization: Geneva, Switzerland. 